\title{
Ruptured Ovarian Ectopic Pregnancy after Interval of Tubal Ligation
}

\author{
${ }^{1}$ Poonam Raikwar, ${ }^{2}$ Vijeta Jain, ${ }^{3}$ Ramsharan Raikwar
}

\begin{abstract}
We report a case of a woman presenting in a state of shock with classic symptoms of rupture ectopic pregnancy. She had a history of tubal ligation done two years back. Laparoscopic surgery was done and a diagnosis of ruptured ectopic ovarian pregnancy was made.
\end{abstract}

Keywords: Ectopic post, Ovarian pregnancy, Tubal ligation

How to cite this article: Raikwar P, Jain V, Raikwar R. Ruptured Ovarian Ectopic Pregnancy after Interval of Tubal Ligation. Int J Gynecol Endsc 2017;1(1):44-45.

Source of support: Nil

Conflict of interest: None

\section{INTRODUCTION}

Ectopic tubal gestation following sterilization accounts for $12 \%$ of all ectopic pregnancies. ${ }^{1}$ Ovarian pregnancy is rare and remains a diagnostic and management challenge, especially in settings where health resources are stretched. ${ }^{2}$ We report a case of primary ovarian pregnancy which occurred 2 years after bilateral tubal sterilization.

\section{CASE REPORT}

A 28-year-old female with P4L4 came with complaints of lower abdominal pain with giddiness. Her last menstrual period was 2 months back. Her tubal ligation was done 2 years back and urine pregnancy test was positive. On general examination, patient was conscious, her blood pressure was $90 / 70 \mathrm{~mm} \mathrm{Hg}$, and pulse 100 per minute, she was severely anemic with pallor $2+$, and per abdomen tenderness was present in right lower abdomen. On pelvic examination, uterus was in normal size of $4 \times 4 \mathrm{~cm}$ and irregular tender mass was felt on right side. Cervical excitation was positive, and os was closed. On sonography, a $6.6 \times 4.4 \mathrm{~cm}$ heterogeneous soft tissue mass in

\footnotetext{
${ }^{1}$ Senior Consultant, ${ }^{2,3}$ Consultant

1,2Department of Obstetrics and Gynecology, ESIC Hospital Indore, Madhya Pradesh, India

${ }^{3}$ Department of Surgery, Mahatma Gandhi Memorial Medical College, Indore, Madhya Pradesh, India

Corresponding Author: Poonam Raikwar, Senior Consultant Department of Obstetrics and Gynecology, ESIC Hospital, Indore Madhya Pradesh, India, e-mail: Poonamraikar219@gmail.com
}

right adnexa and fluid in peritoneal cavity (Fig. 1) were found.

A diagnosis of ruptured ectopic pregnancy was made and laparoscopy was carried out intraoperatively, hemoperitoneum of around $2 \mathrm{~L}$ was seen, right ovary was ruptured with active bleeding. Bilateral tube was normal. Right-sided salpingectomy with oophorectomy was performed. Left side tube was religated, postoperative period was uneventful, and tissue was sent for histopathological examination.

Gross examination: The fallopian tube measured $4.5 \mathrm{~cm}$ long with no evidence of rupture. The ovary measured $6 \times 5 \times 2 \mathrm{~cm}$ and showed ruptured hemorrhagic clots (Fig. 2).

Histological examination: Histological examination of the ovary showed chorionic villi embedded in ovarian parenchymal tissue with surrounding hemorrhage and necrosis. Fallopian tube was unremarkable (Fig. 3).

So final diagnosis of ectopic ovarian gestation was confirmed.

\section{DISCUSSION}

Ovarian pregnancy results from the fertilization of a trapped ovum within the follicle or corpus luteum at the time of rupture. ${ }^{3,4}$ Implantation within the ovarian stroma is aided by secretions of the corpus luteum. The fertilized ovum undergoes development with formation of placental tissue, amniotic sac, and fetus. ${ }^{4}$ However, normal implantation occurs within the uterine cavity.

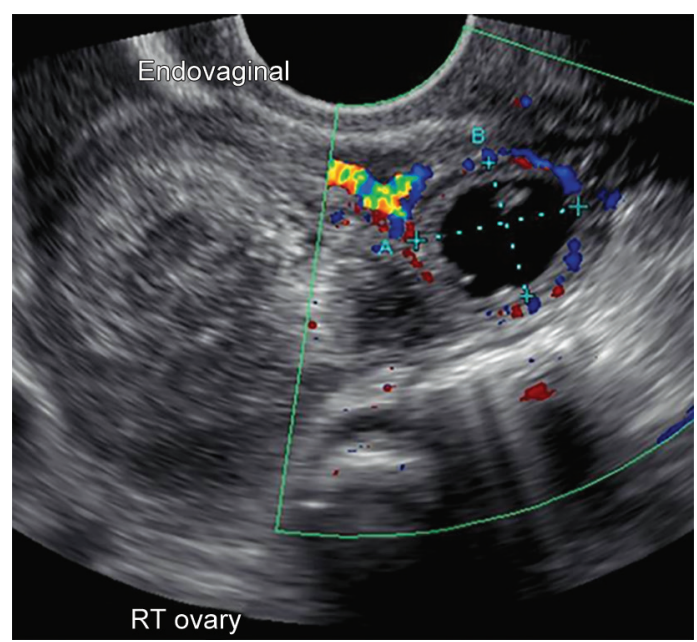

Fig. 1: Ultrasound image demonstrating a mass in right adnexa measuring $6.6 \times 4.4 \mathrm{~cm}$ and no intrauterine pregnancy 


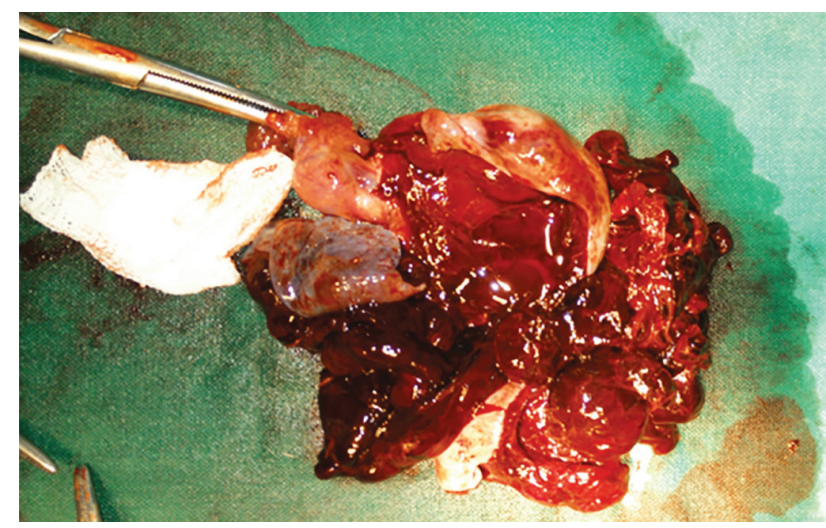

Fig. 2: Ovary with tubes and clot ovary showing rupture

The incidence of ectopic gestation is $4.5 / 1,000$ to $16.8 / 1,000$ pregnancies. ${ }^{3,5}$ Tubal pregnancy with an incidence rate of $1 / 200$ to $1 / 300$ pregnancies is the commonest form. 3,6 The incidence of ovarian pregnancy ranges from $1 / 6,000$ to $1 / 40,000$ pregnancies. ${ }^{7,8}$ Ovarian pregnancy constitutes 0.5 to $6 \%$ of all ectopic pregnancies. ${ }^{7,9,10} \mathrm{It}$ is generally seen in cases following intrauterine contraceptive device section. So far, only a few cases of ovarian pregnancy following tubal ligation have been reported as per the literature survey. Ectopic gestation after tubal ligation is due to recanalization or formation of a tuboperitoneal fistula. Spermatozoa may pass through, but the fertilized ovum fails to go through, so implantation occurs in the distal tubal segment. ${ }^{11,12}$ A case by Wittich ${ }^{13}$ in 2004 has reported that the ovarian ectopic pregnancy occurs following postpartum sterilization as the tubes are edematous, friable, and congested, resulting in incomplete occlusion of tubes. Another case by Changsan et $\mathrm{al}^{14}$ reported ovarian pregnancy after tubal ligation.

\section{CONCLUSION}

Ovarian pregnancy is a rare variant of ectopic implantation. Incidence of ovarian pregnancy after interval tubal ligation procedure has been reported rarely, but must be extremely rare.

We would like to emphasize the fact that though ectopic tubal or ovarian gestation is rare after tubal ligation, one has to consider this possibility when the patient comes with typical signs and symptoms of ectopic gestation following history of amenorrhea.

\section{REFERENCES}

1. Chakravarti S, Shardlow J. Tubal pregnancy after sterilization. Br J Obstet Gynaecol 1975 Jan;82(1):58-60.

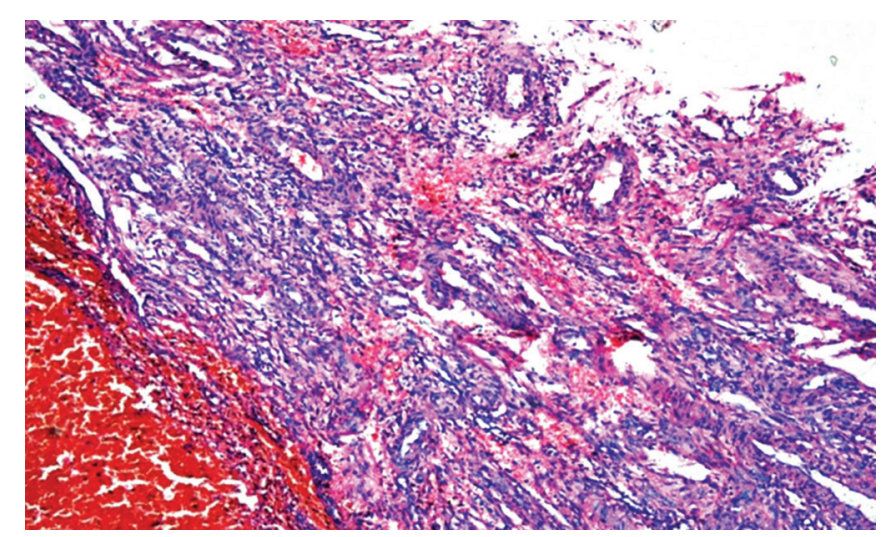

Fig. 3: Histopathological section of ovary showing ovarian tissue with chorionic villi with hemorrhage and necrosis

2. Oliver R, Malik M, Coker A, Morris J. Management of extra-tubal and rare ectopic pregnancies: case series and review of current literature. Arch Gynecol Obstet 2007 Aug;276(2):125-131.

3. Novak, ER.; Woodruff, JD. Ovarian pregnancy. In: Novak's gynaecology and obstetric pathology with clinical and endocrine relations. Philadelphia: Saunders; 1967. p. 432-450.

4. Crum, CP. The female genital tract. In: Cotran, RS.; Kumar, V.; Collins, T., editors. Robbin's pathologic basis of disease. Philadelphia: Saunders; 1999. p. 1079-1080.

5. Bustos López HH, Rojas-Poceros G, Barrón Vallejo J, Cintora Zamudio S, Kably Ambe A, Valle RF. Conservative laparoscopic treatment of bilateral ectopic pregnancy. 2 case reports and review of the literature. Gynecol Obstet Mex 1998 Jan;66:13-17.

6. Raziel A, Schachter M, Mordechai E, Friedler S, Panski M, Ron-El R. Ovarian pregnancy - a 12-year experience of 19 cases in one institution. Eur J Obstet Gynecol Reprod Biol 2004 May;114(1):92-96.

7. Kraiem J, Bouden S, Ounaissa F, Falfoul A. Ovarian pregnancy: the situation in 2003. A report of four cases and literature review. Tunis Med 2004 Sep;82(9):858-866.

8. Royal College of Obstetrician and Gynaecologists. The management of tubal pregnancy. RCOG Guideline No 21. London: RCOG Press; 2004.

9. Itoh H, Ishihara A, Koita H, Hatakeyama K, Seguchi T, Akiyama Y, Kataoka H. Ovarian pregnancy: report of four cases and review of the literature. Pathol Int 2003 Nov;53(11):806-809.

10. Raziel A, Mordechai E, Schachter M, Friedler S, Pansky M, Ron-El R. A comparison of the incidence, presentation, and management of ovarian pregnancies between two periods of time. J Am Assoc Gynecol Laparosc 2004 May;11(12):191-194.

11. Davis MR. Recurrent ectopic pregnancy after tubal sterilization. Obstet Gynecol 1986 Sep;68(3 Suppl):44S-45S.

12. Stock RJ, Nelson KJ. Ectopic pregnancy subsequent to sterilization: histologic evaluation and clinical implications. Fertil Steril 1984 Aug;42(2):211-215.

13. Wittich AC. Primary ovarian pregnancy after postpartum bilateral tubal ligation: a case report. J Reprod Med 2004 Sep;49(9):759-761.

14. Changsan V, Mundhra R. J Family Reprod Health 2013 Dec;7(4). 